DOI: https://doi.org/10.47405/mjssh.v6i6.819

\begin{tabular}{|c|c|}
\hline$\sqrt{10}$ & Malaysian Journal of Social Sciences and Humanities (MJSSH) \\
\hline $\begin{array}{l}\text { Malaysian Journal of } \\
\text { socai sciences and }\end{array}$ & Volume 6, Issue 6, June 2021 \\
\hline (MJ-ssH) & e-ISSN : 2504-8562 \\
\hline & $\begin{array}{l}\text { Journal home page: } \\
\text { www.msocialsciences.com }\end{array}$ \\
\hline
\end{tabular}

\title{
Amalan Kepimpinan Multidimensi Pengetua dan Norma-Norma Budaya di MRSM
}

\author{
Faridah Darus ${ }^{1}$, Mohd Khairuddin @Jerry Abdullah ${ }^{1}$ \\ ${ }^{1}$ Fakulti Psikologi dan Pendidikan, Universiti Malaysia Sabah (UMS), Malaysia \\ Correspondence: Faridah Binti Darus (artikelfd@gmail.com)
}

\begin{abstract}
Abstrak
Penyelidikan ini dijalankan bertujuan mengenal pasti tahap perbezaan skor min kepimpinan multidimensi pengetua dan norma-norma budaya dari aspek lokasi dan jantina guru di Maktab Rendah Sains MARA. Kajian menggunakan kaedah tinjauan. Beberapa teknik pensampelan digunakan iaitu pensampelan tiga tahap iaitu tahap satu (1) ialah pensampelan rawak kelompok besar; tahap dua (2) ialah pensampelan rawak kelompok kecil dalam kelompok besar; tahap tiga (3) ialah pensampelan rawak elemen dalam kelompok kecil dengan mengedarkan satu set borang soal selidik yang telah diadaptasi daripada penyelidik asal. Seramai 363 orang responden yang terdiri daripada ketua-ketua jabatan akademik dan guru-guru kanan subjek di 20 buah MRSM seluruh Malaysia telah menjawab soal selidik yang diedarkan. Data dianalisis menggunakan perisian IBM SPSS. Dapatan kajian menunjukkan tahap kepimpinan pengetua adalah sangat tinggi dan tahap norma-norma budaya hanyalah tahap tinggi. Seterusnya kepimpinan multidimensi pengetua dan norma-norma budaya terdapat perbezaan skor min yang signifikan pada aras $\mathrm{p}<.05$ dari aspek lokasi. Kepimpinan multidimensi pengetua dari aspek jantina tidak terdapat perbezaan yang signifikan pada aras $\mathrm{p}<.05$ tetapi terdapat perbezaan yang signifikan pada aras $\mathrm{p}<.05$ dalam norma-norma budaya dari aspek jantina.
\end{abstract}

Kata kunci: kepimpinan multidimensi pengetua, norma-norma budaya, MRSM

\section{Principals' Multidimensional Leadership Practices and Cultural Norms in MRSM}

\begin{abstract}
This research was conducted to identify the level of difference in the mean score of multidimensional leadership of principals and cultural norms from the aspect of location and gender of teachers in the MARA Junior College of Science. The study used a survey method. Several sampling techniques are used, namely three -level sampling, namely level one (1) is large group random sampling; stage two (2) is random sampling of small clusters within large clusters; level three (3) is random sampling of elements in small groups by distributing a set of questionnaires that have been adapted from the original researcher. A total of 363 respondents consisting of heads of academic departments and senior subject teachers in 20 MRSMs throughout Malaysia answered the questionnaire distributed. Data were analyzed using IBM SPSS software. The findings of the study show that the level of leadership of principals is very high and the level of cultural norms is high. Next to the multidimensional leadership of principals and cultural norms there was a significant mean score difference at the level of $p<.05$ from the aspect of location. The multidimensional leadership of principals did not have a significant
\end{abstract}


DOI: https://doi.org/10.47405/mjssh.v6i6.819

difference at the level of $p<.05$ but there was a significant difference at the level of $p<.05$ in cultural norms from the aspect of gender.

Keywords: principal multidimensional leadership, cultural norms, MRSM

\section{Pengenalan}

Amalan kepimpinan yang multidimensi boleh mendatangkan keberkesanan dalam pendidikan (Bolman \& Deal, 2003). Pengetua yang mengamalkan kepimpinan yang berkesan boleh mempengaruhi budaya kerja guru, murid dan kakitangan untuk menerima kepimpinannya ke arah mencapai tujuan dan matlamat yang telah dilestarikan. Selain itu, matlamat di sekolah akan tercapai kerana direalisasikan oleh pemimpin sekolah yang berkesan, berbagai-bagai, berkualiti dan cemerlang serta mantap dalam kepimpinan. Dalam erti kata lain, kepimpinan multidimensi dilihat sebagai faktor yang memacu ke arah penghasilan pendidikan yang berkualiti. Kajian Janary (2016) menunjukkan amalan kepimpinan guru besar lebih cenderung kepada sumber manusia, namun strategi politik dan simbolik mempengaruhi keprihatinan guru dalam tugas terutamanya lebih kepada prihatin impak. Kajian Halimah dan Dg Norizah (2017) menunjukkan para pengurus sekolah wajar diberikan pendedahan yang sewajarnya agar lebih memahami konsep pengajaran dan pembelajaran Abad 21 ini.

Seterusnya, kunci bagi pelaksanaan dalam membangunkan sesuatu program pendidikan di sekolah ialah budaya (Rhodes, Steven \& Hemmings, 2011). Budaya sekolah mempengaruhi cara guru, pentadbir sekolah dan pelajar untuk melakukan sesuatu tindakan. Selain itu, budaya sekolah akan menimbulkan impak terhadap proses pembangunan pendidikan di sekolah. Daripada analisis yang dijalankan oleh Mohana et. al, (2019), didapati tahap beban kerja guru di MRSM yang paling tinggi adalah di bawah beban tugas bukan akademik iaitu memastikan pelajar untuk mematuhi peraturan di MRSM. Kajian Kasinitz et al., (2008) menunjukkan bahawa bagi mengekalkan budaya sekolah bukannya mudah, kecuali sekiranya sesebuah sekolah itu bersedia memiliki struktur yang menyokong pembudayaan sekolah dan ini akan memberi kesan dalam aspek kestabilan organisasi, kesepaduan, kebolehan menyesuaikan diri dalam organisasi (Kythreoti et al., 2010).

\section{Sorotan Literatur}

Kepimpinan multidimensi ialah kepimpinan yang mengandungi empa rangka kepimpinan iaitu struktural, simbolik, sumber manusia dan politik, yang telah dihasilkan oleh Bolman dan Deal. Kepimpinan struktural merupakan kemahiran analitikal dan pengurusan organisasi dan kepimpinan simbolik pula merujuk pada ciri kepimpinan yang menyokong dan partisipatif. Sementara itu, kepimpinan politik pula merupakan pelbagai kekuatan berkaitan kuasa dan sensitiviti politik. Kepimpinan sumber manusia pula merujuk kepada inspirasi dan karisma pemimpin (Bolman \& Deal 1991, 1997). Walaupun terdapat teori dan model kepimpinan yang berbeza, namun para penyelidik berpendapat teori kepimpinan multidimensi adalah lebih berpadanan untuk mengetahui proses kepimpinan dalam institusi pendidikan (Aieman 2013; Bolman \& Deal 1991, 1997; Davis, 2012). Model kepimpinan multidimensi menunjukkan gambaran yang lebih tepat, komprehensif dan holistik berkaitan kepimpinan dalam organisasi berbanding model kepimpinan yang memiliki dua dimensi kerana kepimpinan multidimensi mampu menunjukkan gambaran menyeluruh cara pemimpin memahami dan mentafsir organisasi (Lokman Mohd Tahir et al., 2011). Model ini turut dijadikan panduan kepada pemimpin cara kepimpinan yang berbagai-bagai digunakan dalam situasi yang berbeza (Lokman Mohd Tahir \& Aini Kaman, 2011). Bolman dan Deal (1984) menjelaskan bahawa amalan orientasi kepimpinan berbagai-bagai atau multidimensi adalah amat sesuai bagi persekitaran yang perlukan perubahan. 
Menurut Hoy dan Miskel (2005), norma budaya wajar dikuatkuasakan dan disokong; kegagalan seseorang untuk menyesuaikan diri dengan norma akan mengakibatkan tindakan diambil terhadap ahliahli dalam sesuatu kumpulan itu. Malah Schein (1992) juga menjelaskan bahawa budaya wujud daripada tiga sumber iaitu kepercayaan, nilai dan andaian daripada pengasas organisasi, pengalaman dari pembelajaran ahli kumpulan apabila organisasi berkembang; dan kepercayaan baharu, nilai dan andaian yang dibawa ahli dan pemimpin baru. Beliau juga menyatakan antara sumber yang boleh dikaji secara kuantitatif ialah norma budaya. Kajian berkaitan keberkesanan sekolah oleh Purkey dan Smith (1982) memberi bukti bahawa keberkesanan sekolah berbeza kerana keadaan budaya dari segi struktur, proses, persekitaran nilai dan norma yang membawa guru dan pelajar menuju kejayaan bagi pengajaran dan pembelajaran. Seterusnya Saphier dan King (1985) menyokong kajian Purkey dan Smith (1982) dengan menyatakan terdapat dua belas norma budaya yang mempunyai hubungan positif tentang budaya sekolah. Apabila norma budaya sekolah itu kuat maka peningkatan amalan pengajaran dan pembelajaran adalah amat signifikan dan begitu sebaliknya jika norma yang lemah maka peningkatan amat perlahan (Saphier \& King, 1985).

\section{Metod Kajian}

Jika hanya bergantung kepada satu cara daripada kerangka Bolman dan Deal (2003) akan menyebabkan golongan pemimpin sekolah bertumpu hanya dalam sesuatu kerangka. Jika keempat-empat kerangka itu digabungkan atau pelbagai kerangka maka menunjukkan organisasi dapat distabilkan. Dalam jadual 1 menunjukkan ringkasan model kerangka Bolman dan Deal dari segi konsep, bentuk kepimpinan dan asas cabaran kepimpinan.

Jadual 1: Ringkasan Kerangka Kemimpinan

\begin{tabular}{lllll}
\hline & Struktural & Sumber Manusia & Politik & Simbolik \\
\hline Konsep & $\begin{array}{l}\text { Peraturan, } \\
\text { peranan, } \\
\text { matlamat, polisi } \\
\text { teknologi, } \\
\text { persekitaran, }\end{array}$ & $\begin{array}{l}\text { Keperluan, } \\
\text { kemahiran, } \\
\text { perhubungan, }\end{array}$ & $\begin{array}{l}\text { Kuasa, konflik, } \\
\text { persaingan, } \\
\text { politik }\end{array}$ & $\begin{array}{l}\text { Budaya, } \\
\text { tokoh }\end{array}$ \\
$\begin{array}{l}\text { Brkitek sosial } \\
\text { kepimpinan }\end{array}$ & Penurunan kuasa & sokongan & inspirasi \\
$\begin{array}{l}\text { Asas cabaran } \\
\text { kepimpinan }\end{array}$ & $\begin{array}{l}\text { Menstrukturkan } \\
\text { cabaran, } \\
\text { teknologi, } \\
\text { persekitaran }\end{array}$ & $\begin{array}{l}\text { Kesepaduan } \\
\text { organisasi/ } \\
\text { keperluan manusia }\end{array}$ & $\begin{array}{l}\text { Berpusatkan } \\
\text { kuasa }\end{array}$ & $\begin{array}{l}\text { Wujud } \\
\text { kepercayaan }\end{array}$ \\
& & & \\
\hline
\end{tabular}

Sumber: Bolman (2003)

Berdasarkan jadual 1, Bolman dan Deal (1997) yakin bahawa pemimpin akan mengaplikasikan kerangka kepimpinan struktural, simbolik, sumber manusia atau politik dalam melaksanakan keputusan dan mengatasi masalah organisasi. Mereka juga berpendapat setiap kerangka kepimpinan mempunyai fungsi dan proses kepimpinan yang perlu diamalkan oleh pemimpin dalam situasi yang berlainan. Setiap kerangka wajar diamalkan berdasarkan situasi dan kehendak organisasi (Bolman \& Deal, 1997) atau diguna secara sejajar berdasarkan jangka hayat organisasi (Daft, 1999). Namun begitu, Daft (1999) lebih memandang asas pengurusan organisasi wajar diwujudkan mulai daripada struktural iaitu pemantapan organisasi, selepas itu sumber manusia agar wujud kesetiaan kakitangan terhadap organisasi. Seterusnya, diikuti oleh kerangka kepimpinan politik bagi menyelesaikan isu konflik dan pengesahan sebagai kuasa pemimpin dalam organisasi. Akhir sekali ialah kerangka simbolik iaitu wujudkan mengenali identiti dan nilai dalam kalangan organisasi.

Aspek norma-norma budaya yang sesuai dengan model Schein (1985) iaitu kepercayaan, nilai dan andaian berasas organisasi adalah juga merupakan norma budaya yang akan menunjukkan gambaran yang lebih tepat tingkahlaku guru-guru dalam meningkatkan kepedulian terhadap kerja. 


\section{Rajah 1 : Model Peringkat Budaya Organisasi}

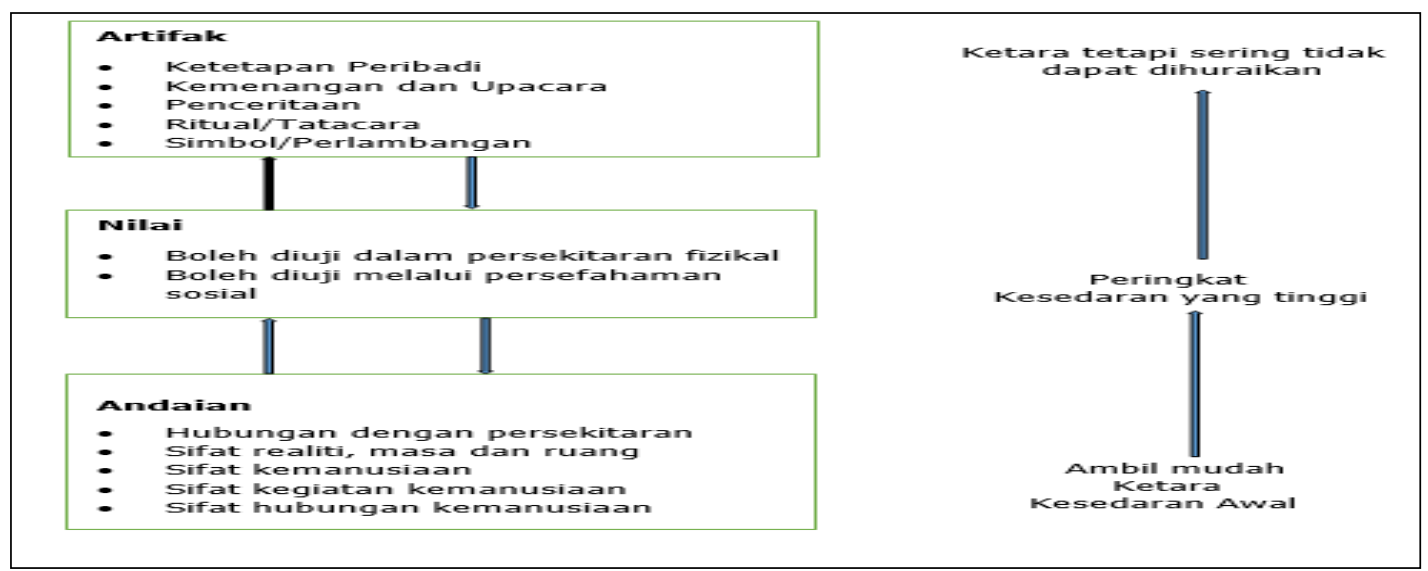

Sumber : Schein (1985)

Reka bentuk kajian ini adalah kajian kuantitatif. Proses pengumpulan data kajian telah menggunakan kaedah tinjauan bagi mengetahui penilaian dan fenomena pengaruh pemboleh ubah bebas ke atas pemboleh ubah bersandar, satu tinjauan yang meluas diperlukan ke atas populasi yang besar dan dalam kajian ini iaitu ketua-ketua jabatan akademik dan guru-guru kanan subjek MRSM di seluruh Malaysia. Pengkaji menetapkan saiz sampel seramai 363 orang selari dengan rules of thumb yang dicadangkan oleh Roscoe (1975) yang menyatakan bahawa saiz sampel yang lebih besar daripada 30 dan lebih kecil daripada 500 adalah sesuai untuk kebanyakan kajian (Sekaran, 2000). Pemilihan sampel dengan teknik ini melibatkan pemilihan kelompok dalam kelompok (Gay \& Diehl, 1996). Kajian ini menggunakan pensampelan tiga tahap (three stag sampling) iaitu tahap satu (1) ialah pensampelan rawak kelompok besar; tahap dua (2) ialah pensampelan rawak kelompok kecil dalam kelompok besar; tahap tiga (3) ialah pensampelan rawak elemen dalam kelompok kecil (Neuman, 2006).

Instrumen kajian untuk kepimpinan multidimensi pengetua diperoleh daripada kajian Lokman Mohd Tahir et al., (2017) iaitu inventori orientasi kepimpinan yang dibuat penyesuaian daripada orientasi kepimpinan (Bolman dan Deal, 1990, 1997). Namun dalam kajian ini pengkaji hanya mengukur tingkahlaku kepimpinan pengetua yang merangkumi 26 item. Soal selidik yang digunakan untuk norma-norma budaya adalah dibuat penyesuaian daripada set norma budaya sekolah (Philips, 1993).

Kajian rintis dilaksanakan untuk menguji instrumen yang digunakan sama ada ia memenuhi ciri-ciri kebolehpercayaan. Kajian ini telah melakukan ujian rintis bagi memastikan instrumen kajian jelas, menarik, tidak mengelirukan responden, tekal dan mudah difahami. Kajian rintis yang telah dilaksanakan oleh pengkaji melalui pentadbiran yang sama dengan kajian sebenar. Setelah kajian rintis dijalankan, nilai pekali Cronbach Alpha dinilai untuk memastikan tahap kebolehpercayaan instrumen bagi kajian ini. Pengkaji telah mengambil 111 orang responden ketua-ketua jabatan dan guru-guru kanan subjek di lima buah MRSM seluruh Malaysia. Responden yang dipilih bagi menjalani kajian rintis ini memiliki ciri-ciri yang hampir sama dengan responden bagi kajian sebenar. Instrumen soal selidik yang digunakan dalam kajian ini memiliki kebolehpercayaan yang tinggi dan boleh digunakan tanpa melalui proses penambahbaikan, pengubahsuaian, dan juga penyingkiran.

Analisis statistik deskriptif digunakan untuk menghuraikan data mentah supaya boleh difahami dengan melakukan penyusunan secara bermakna. Analisis statistik deskriptif digunakan untuk menghuraikan melalui ukuran kecenderungan memusat ( $\mathrm{min}$ ), indeks kebolehubahan (sisihan piawai) dan juga peratusan dan kekerapan. Tambahan pula, ujian kecenderungan memusat, indeks kebolehubahan, peratusan dan kekerapan digunakan untuk memberi gambaran mengenai tahap kepimpinan multidimensi pengetua dan norma-norma budaya. 
DOI: https://doi.org/10.47405/mjssh.v6i6.819

Jadual 2 : Interprestasi Skor Min Kepimpinan Multidimensi Pengetua

\begin{tabular}{cc}
\hline Skor Min & Aras \\
\hline $4.30-5.00$ & Sangat Tinggi \\
$3.50-4.29$ & Tinggi \\
$2.70-3.49$ & Sederhana \\
$1.90-2.69$ & Rendah \\
$1.00-1.89$ & Sangat Rendah \\
\hline
\end{tabular}

Sumber: Izza dan Yahya (2014)

Jadual 3 : Interpretasi Skor Min Norma-Norma Budaya

\begin{tabular}{cc}
\hline Skor Min & Aras \\
\hline $3.68-5.00$ & Tinggi \\
$1.35-3.67$ & Sederhana \\
$1.00-1.34$ & Rendah \\
\hline
\end{tabular}

Sumber: Creswell (2009)

\section{Dapatan Kajian}

Jadual 4 menunjukkan tahap kepimpinan multidimensi pengetua. Tahap kepimpinan multidimensi pengetua berada pada tahap yang sangat tinggi $(\mathrm{Min}=4.35, \mathrm{SP}=0.453$ ). Berdasarkan skor min dalam empat dimensi kepimpinan multidimensi pengetua jelas menunjukkan taburan skor min sangat tinggi adalah struktural (Min=4.45, $\mathrm{SP}=0.484)$, simbolik (Min=4.40, $\mathrm{SP}=0.494)$, dan sumber manusia $(\mathrm{Min}=4.31, \mathrm{SP}=0.500)$.

Jadual 4: Tahap Kepimpinan Multidimensi Pengetua

\begin{tabular}{lccl}
\hline Dimensi Kepimpinan Multidimensi & M & SP & Tahap \\
\hline Struktural & 4.45 & .484 & Sangat Tinggi \\
Simbolik & 4.40 & .494 & Sangat Tinggi \\
Sumber Manusia & 4.31 & .500 & Sangat Tinggi \\
Politik & 4.23 & .502 & Tinggi \\
\hline Kepimpinan Multidimensi & 4.35 & .453 & \\
\hline
\end{tabular}

Jadual 5 menunjukkan tahap norma-norma budaya. Dapatan kajian menunjukkan skor min pada tahap yang tinggi iaitu $(\mathrm{Min}=4.02, \mathrm{SP}=0422)$. Kolaboratif profesional menunjukkan skor min tertinggi (Min=4.15, SP=0.479), keyakinan diri (Min=4.02, SP=0.533), dan hubungan keserakanan (Min=3.90,SP=0.506).

Jadual 5: Dimensi Norma-Norma Budaya

\begin{tabular}{lllll}
\hline Dimensi Norma-Norma Budaya & M & SP & Tahap & \\
\hline Kolaboratif Profesional & 4.15 & .479 & & Tinggi \\
Keyakinan Diri & 4.02 & .533 & Tinggi & \\
Hubungan Keserakanan & 3.90 & .506 & Tinggi & \\
\hline Norma-Norma Budaya & 4.02 & .422 & & \\
\hline
\end{tabular}

Jadual 6 memaparkan keputusan analisis analisis keseluruhan bagi kepimpinan multidimensi dari aspek Zon MRSM menunjukkan skor min sangat tinggi ( $M=4.35$, SD.453). Zon Selatan menunjukkan skor 
min paling tinggi iaitu (M=4.46, SD.469) dan Zon Borneo menunjukkan skor min paling rendah $(\mathrm{M}=4.13, \mathrm{SD} .469)$.

Jadual 6: Skor Min kepimpinan Multidimensi Dari Aspek Lokasi

\begin{tabular}{lllllll}
\hline \multirow{5}{*}{ Multidimensi } & & & & & \\
& Zon Utara & N & M & SD & Min & Mak \\
& Zon Tengah & 66 & 4.37 & .390 & 4 & 5 \\
& Zon Timur & 68 & 4.36 & .477 & 3 & 5 \\
& Zon Selatan & 71 & 4.43 & .417 & 4 & 5 \\
& Zon Borneo & 65 & 4.13 & .469 & 3 & 5 \\
Struktural & Total & 343 & 4.35 & .453 & 3 & 5 \\
& Zon Utara & 73 & 4.45 & .439 & 3 & 5 \\
& Zon Tengah & 66 & 4.47 & .477 & 3 & 5 \\
& Zon Timur & 68 & 4.55 & .467 & 4 & 5 \\
& Zon Selatan & 71 & 4.52 & .479 & 3 & 5 \\
\multirow{5}{*}{ Simbolik } & Zon Borneo & 65 & 4.23 & .509 & 3 & 5 \\
& Total & 343 & 4.45 & .484 & 3 & 5 \\
& Zon Utara & 73 & 4.46 & .438 & 3 & 5 \\
& Zon Tengah & 66 & 4.40 & .510 & 3 & 5 \\
& Zon Timur & 68 & 4.43 & .476 & 4 & 5 \\
\multirow{5}{*}{ Mumber } & Zon Selatan & 71 & 4.51 & .479 & 3 & 5 \\
& Zon Borneo & 65 & 4.15 & .507 & 3 & 5 \\
& Total & 343 & 4.40 & .494 & 3 & 5 \\
& Zon Utara & 73 & 4.31 & .415 & 4 & 5 \\
& Zon Tengah & 66 & 4.31 & .559 & 2 & 5 \\
& Zon Timur & 68 & 4.41 & .458 & 3 & 5 \\
& Zon Selatan & 71 & 4.41 & .541 & 2 & 5 \\
& Zon Borneo & 65 & 4.10 & .463 & 3 & 5 \\
& Total & 343 & 4.31 & .500 & 2 & 5 \\
& Zon Utara & 73 & 4.23 & .449 & 4 & 5 \\
& Zon Tengah & 66 & 4.25 & .546 & 2 & 5 \\
& Zon Timur & 68 & 4.31 & .453 & 3 & 5 \\
& Zon Selatan & 71 & 4.36 & .527 & 3 & 5 \\
& Zon Borneo & 65 & 4.01 & .471 & 3 & 5 \\
& Total & 343 & 4.23 & .502 & 2 & 5 \\
\hline
\end{tabular}

Jadual 7 memaparkan keputusan analisis menunjukkan keputusan analisis keseluruhan bagi normanorma budaya dari aspek Zon MRSM menunjukkan skor min tinggi $(M=4.02$, SD .422). Zon Timur menunjukkan skor min tinggi iaitu (M=4.19, SD .423) dan Zon Borneo menunjukkan skor min paling rendah $(\mathrm{M}=3.89$, SD .487).

Jadual 7: Skor Min Norma-Norma Budaya Dari Aspek Lokasi

\begin{tabular}{lllllll}
\hline & & & & & \\
& & N & M & SD & Min & Mak \\
\hline Norma-Norma Zon Utara & 73 & 4.09 & .346 & 3 & 5 \\
Budaya & Zon Tengah & 66 & 3.97 & .389 & 3 & 5 \\
& Zon Timur & 68 & 4.19 & .423 & 3 & 5 \\
& Zon Selatan & 71 & 3.94 & .402 & 3 & 5 \\
& Zon Borneo & 65 & 3.89 & .487 & 3 & 5 \\
Kolaboratif & Total & 343 & 4.02 & .422 & 3 & 5 \\
Profesioanl & Zon Utara & 73 & 4.16 & .446 & 3 & 5 \\
& Zon Tengah & 66 & 4.12 & .430 & 3 & 5
\end{tabular}


DOI: https://doi.org/10.47405/mjssh.v6i6.819

\begin{tabular}{lllllll} 
& Zon Timur & 68 & 4.38 & .468 & 3 & 5 \\
& Zon Selatan & 71 & 4.07 & .475 & 3 & 5 \\
& Zon Borneo & 65 & 4.05 & .513 & 3 & 5 \\
Keyakinan & Total & 343 & 4.15 & .479 & 3 & 5 \\
Diri & Zon Utara & 73 & 4.15 & .454 & 3 & 5 \\
& Zon Tengah & 66 & 3.94 & .525 & 2 & 5 \\
& Zon Timur & 68 & 4.21 & .533 & 3 & 6 \\
& Zon Selatan & 71 & 3.90 & .502 & 3 & 6 \\
& Zon Borneo & 65 & 3.88 & .576 & 2 & 5 \\
Hubungan & Total & 343 & 4.02 & .533 & 2 & 6 \\
& Zon Utara & 73 & 3.99 & .400 & 3 & 5 \\
& Zon Tengah & 66 & 3.82 & .541 & 2 & 5 \\
& Zon Timur & 68 & 4.06 & .498 & 3 & 5 \\
& Zon Selatan & 71 & 3.85 & .443 & 3 & 5 \\
& Zon Borneo & 65 & 3.76 & .590 & 2 & 5 \\
& Total & 343 & 3.90 & .506 & 2 & 5 \\
\hline
\end{tabular}

Jadual 8 memaparkan keputusan analisis skor min kepimpinan multidimensi dari aspek jantina guru. Pemilihan oleh guru lelaki adalah Struktural yang menunjukkan skor min paling tinggi iaitu $(\mathrm{M}=4.47$, SD .508) dan politik menunjukkan skor min paling rendah ( $M=4.29, \mathrm{SD} .548)$. Pemilihan oleh guru perempuan juga adalah struktural yang menunjukkan skor min paling tinggi $(\mathrm{M}=4.44, \mathrm{SD} .472)$ dan politik menunjukkan skor min paling rendah ( $\mathrm{M}=4.20$, SD .474).

Jadual 8: Skor Min Kepimpinan Multidimensi Pengetua Dari Aspek Jantina

\begin{tabular}{lllll}
\hline & & & & \\
& & N & SD \\
\hline Multidimensi & Lelaki & 119 & 4.39 & .487 \\
& Perempuan & 224 & 4.33 & .434 \\
Struktural & Total & 343 & 4.35 & .453 \\
& Lelaki & 119 & 4.47 & .508 \\
Simbolik & Perempuan & 224 & 4.44 & .477 \\
& Total & 343 & 4.45 & .484 \\
Sumber Manusia & Lelaki & 119 & 4.40 & .525 \\
& Perempuan & 224 & 4.39 & .478 \\
& Total & 343 & 4.40 & .494 \\
Politik & Lelaki & 119 & 4.36 & .546 \\
& Perempuan & 66 & 4.28 & .472 \\
& Total & 343 & 4.31 & .500 \\
& Lelaki & 119 & 4.29 & .548 \\
& Perempuan & 224 & 4.20 & .474 \\
& Total & 343 & 4.23 & .502 \\
\hline
\end{tabular}

Jadual 9 memaparkan keputusan analisis skor min kepimpinan multidimensi dari aspek jantina guru. Pemilihan oleh guru lelaki adalah Struktural yang menunjukkan skor min paling tinggi iaitu $(\mathrm{M}=4.47$, SD .508) dan politik menunjukkan skor min paling rendah ( $M=4.29, \mathrm{SD} .548)$. Pemilihan oleh guru perempuan juga adalah struktural yang menunjukkan skor min paling tinggi ( $M=4.44, S D$.472) dan politik menunjukkan skor min paling rendah ( $\mathrm{M}=4.20$, SD .474).

Jadual 9: Skor Min Norma-Norma Budaya Dari Aspek Jantina

\begin{tabular}{lllll}
\hline & & & \\
& & N & M & SD \\
\hline Norma-Norma Budaya & Lelaki & 119 & 4.08 & .431 \\
& Perempuan & 224 & 3.99 & .415
\end{tabular}


DOI: https://doi.org/10.47405/mjssh.v6i6.819

\begin{tabular}{lllll} 
Kolaboratif Profesional & Lelaki & 119 & 4.20 & .515 \\
& Perempuan & 224 & 4.13 & .458 \\
Keyakinan Diri & Lelaki & 119 & 4.04 & .507 \\
& Perempuan & 224 & 4.01 & .547 \\
Hubungan Keserakanan & Lelaki & 119 & 4.00 & .532 \\
& Perempuan & 66 & 3.85 & .484 \\
\hline
\end{tabular}

\section{Perbincangan}

Berdasarkan dapatan ini, pengetua di MRSM menunjukkan kepimpinan struktural yang sangat tinggi iaitu patuh kepada setiap peraturan yang telah ditetapkan dan mementingkan struktur organisasi MRSM dalam menjalankan tugas. Selain itu, pengetua yang mengamalkan kepimpinan struktural akan menilai kualiti kerja setiap guru secara terperinci dan memantau tugas yang diberikan kepada guru. Begitu juga dengan kepimpinan simbolik yang diamalkan oleh pengetua berada pada tahap sangat tinggi. Hal ini bermaksud pengetua memberi penekanan terhadap matlamat organisasi dan sangat kreatif dalam mentadbir MRSM. Tahap yang sangat tinggi juga pada amalan kepimpinan sumber manusia iaitu pengetua memberi kuasa kepada guru dalam melaksanakan tugas seorang yang dapat diajak berbincang dalam menyelesaikan pelbagai masalah. Namun begitu, tahap yang tinggi sahaja pada kepimpinan politik dari aspek berkemampuan mempengaruhi orang untuk mencapai matlamat yang diinginkan dan membina rangkaian yang baik dengan Muafakat (PIBG).

Hal ini menunjukkan bahawa pengetua mengamalkan semua strategi dalam kepimpinan multidimensi di MRSM. Dapatan kajian ini menyokong kajian Mohd khairy Bazli, et.al., (2000) iaitu keempat-empat dimensi kepimpinan multidimensi diamalkan di sekolah daerah Tampin. Kajian Noraziyanah (2019) menunjukkan kepimpinan multidimensi pengetua adalah sangat tinggi di sekolah di beberapa buah sekolah di Malaysia. Kajian Azmira (2019) juga mendapati bahawa pengetua sekolah di daerah Melaka Tengah mengamalkan keempat-empat dimensi kepimpinan yang diperkenalkan oleh Bolman dan Deal (1991; 2003). Kajian yang dijalankan oleh Janary (2016) turut mendapati pengetua mengamalkan keempat-empat dimensi namun begitu pengetua lebih fokus mengamalkan kepimpinan sumber manusia. Dapatan kajian ini juga menyokong kajian Mastura (2013) yang mendapati bahawa pengetua sekolah menengah kluster kecemerlangan daerah Muar melaksanakan keempat-empat kerangka kepimpinan yang diperkenalkan oleh Bolman dan Deal (1991; 2003). Kajian yang dijalankan oleh Shamsudeen (2005) turut mendapati tahap kepimpinan pengetua sekolah menengah swasta melaksanakan keempatempat kerangka namun semuanya hanya pada tahap sederhana menurut penilaian guru. Secara keseluruhan, majoriti berpendapat bahawa norma-norma budaya mereka berada pada tahap tinggi.

Kajian berkaitan norma-norma budaya membuktikan bahawa kesedaran yang tinggi dalam kalangan guru-guru bagi setiap dimensi norma-norma budaya. Kepentingan budaya seperti mana dapatan penyelidik terdahulu mendapati pemimpin sekolah wajar mengetahui lebih awal budaya sekolah sebelum melaksanakan sesuatu perubahan (Nomura, 1999; Leithwood et al., 2001). Oleh yang demikian, penetapan norma-norma budaya wajar mengetahui kehendak matlamat organisasi, iaitu penerimaan guru terhadap amalan baharu dan perubahan yang ingin dibawa di MRSM. Keyakinan diri atau motivasi intrinsik guru amat penting untuk mencapai sesuatu matlamat. Dapatan pengkaji menyokong kajian Perlman (2013) iaitu guru pra-perkhidmatan yang tinggi tahap keyakinan diri juga memiliki pengetahuan profesional dan komitmen yang tinggi.

Guru-guru yang memiliki keyakinan diri yang tinggi akan memudahkan sebarang ikhtiar sekolah bagi merancang sebarang pembaharuan yang akan memberi kesan jangka panjang. Bagi Berry et al. (2010) pula kolaborasi guru secara asasnya menerusi pertukaran idea dan membangunkannya akan menguatkan lagi hubungan keserakanan di sekolah. Dimensi hubungan keserakanan dirujuk sebagai pembangunan profesional yang penting iaitu guru bantu-membantu dalam aspek amalan peningkatan pengajaran, dianggap berguna sebagai kriteria kejayaan sekolah (Brinton, 2007). 
DOI: https://doi.org/10.47405/mjssh.v6i6.819

Kajian yang dijalankan oleh Gun dan Caglayan (2013) berkaitan budaya sekolah di institusi pengajian tinggi mengenal pasti tahap skor min dalam hubungan keserakanan dan kolaboratif adalah sederhana. Namun kekuatan skor min pada tahap tinggi bagi pemboleh ubah dan dimensi norma-norma budaya dalam kajian ini menerangkan bahawa norma-norma yang mempunyai kolaboratif profesional, keyakinan diri dan hubungan keserakanan yang tinggi menunjukkan sifat saling percaya, menghargai idea, menjalankan perancangan bersama-sama, menilai dan bertukar-tukar pendapat tentang amalan pengajaran dan juga menolong rakan-rakan bagi menyelesaikan sesuatu tugasan.

\section{Kesimpulan}

Dalam amalan kepimpinan multidimensi pengetua menunjukkan bahwa tahap kerangka kepimpinan adalah tinggi terutamanya kepada sumber manusia, diikuti struktural, simbolik dan politik. Oleh itu, jelaslah bahawa pengetua di MRSM mengaplikasikan kemampuan bagi melaksanakan strategi kepimpinan berdasarkan situasi dan keperluan organisasi (Bolman \& Deal, 1997). Walaupun dalam kajian ini mendapati amalan kepimpinan multidimensi lebih mengamalkan kepada sumber manusia, namun kepimpinan berstrategik politik dan simbolik memiliki pengaruh juga terhadap kepedulian kerja guru. Hal ini diandaikan bahawa amalan kepimpinan dalam kerangka politik masih diperlukan kerana semasa melaksanakan sebarang pembaharuan atau amalan baharu yang hendak dilakukan akan menghasilkan suasana persaingan bagi menguasai sumber serta konflik dalam tugasan. Kesimpulannya, pemboleh ubah amalan kepimpinan multidimensi, efikasi guru dan norma-norma budaya merupakan pengaruh dan menjadi penyumbang terhadap kepedulian kerja guru MRSM.

\section{Rujukan}

Aieman, A.A.M. (2013). Leadership Frame Preference Of Jordanian Schools' Principals As Perceived By Their Teachers: The Bolman And Deal Four Frames Model European. Journal of Social Sciences, 38(2): $252-262$.

Azmira Ali, (2019). Amalan Kepimpinan Multidimensi Pengetua Dan Hubungan Dengan Kepuasan Kerja Guru Sekolah Menengah Di Daerah Melaka Tengah, Melaka. Sumber: International Journal of Modern Trends in Social Sciences, 2(7).

Berry, B., Daughtrey, A., and Wieder, A. (2010). A better system for schools: Developing, supporting, and retaining effective teachers. New York and Hiliborough, NC; Teachers Network and center for teacher quantity.

Bolman,L.G. and Deal, T.E. (1984). Leading and managing: Effects of context, culture, and gender. Educatioal Administration Quarterly, 30(1), 77-96.

Bolman, L.G. and Deal, T.E. (1991). Reframing Organizations. San Francisco: jossey-Bass.

Bolman, L. G. \& Deal, T. E. (2003). Reframing Organizations: Artistry, Choice and Leadership. Edisi ke-3. San Francisco: Jossey-Bass.

Brinton, C.M. (2007). Comparing perceptions about collaborative culture from certified and noncertified staff members through the adaption of the school culture survey. Unpublished thesis.

D Davis, M.W. (2012). Distributed leadership and school performance (Doctoral dissertation). Retrieved from ProQuest, UMI Dissertations Publishing.aft, R. 1999. Leadership: theory and practice, Orlando, Florida: Harcourt Brace.

Gay, L.R. and Diehl, P.L. (1996). Research Methods for Business and Management. In Hill, R. 1998. "What Sample Size is 'Enough' in Internet Survey Research"? Interpersonal Computing and Technology: An electronic Journal for the 21st Century.

Gun, B. and Caglayn, E. (2013). Implications from the Diagnosis of a School Culture at a Higher Education Institution. Turkish Online Journal of Qualitative Inquiry, 4(1).

Halimah Hj Ag Kanak \& Dg Norizah Binti Ag Kiflee@Dzulkifli (2017). Pengaruh Coaching \& Mentoring dalam Meningkatkan Kemahiran Kepimpinan Pengetua dan Guru Besar di negeri Sabah. Prosiding Simposium Psikologi dan Kesihatan Sosial-I (2017). Universiti Malaysia Sabah. 
Hoy, W.K. and Miskel, C.G. (2005). Educational administration: Theory, Research, And Practice (7th ed.). New York: McGraw Hill.

Janary Anak Lumbai, (2016). Pengaruh Amalan Kepimpinan Berstruktur, Efikasi Guru dan NormaNorma Budaya Terhadap Keprihatinan Tugas Guru Sekolah Kebangsaan di Sarawak. Universiti Malaysia Sabah (Tidak Diterbitkan) (Tesis Doktor Falsafah).

Kasinitz, P., Mollenkopf, J.H., Water,M.G., and Holdaway, J. (2008). Inheriting the city: The children of Immigrants come of age. New York, NY: Rusell Sage Foundation.

Kythreotis, A., Pashiardis, P. and Kyriakides, L. (2010). The influence of school eadership styles and culture on student's achievement in Cyprus primary schools. Journal of Educational Administration, 48(2), 218-240.

Leithwood, K., Jantzi, D. (2001). Transformational school leadership effects: A replication. School Effectiveness \& School Improvement, 10(4): 451-479.

Lokman Mohd Tahir, \& Mohd Anuar Abd Rahman. (2011). Orientasi Kepimpinan Pengetua Sekolah. (M. Z. Bahak, Ed.) (Edisi Pert). Malaysia: UTM PRESS Universiti Teknologi Malaysia.

Lokman Mohd Tahir dan Aini Kaman. (2011). Kepimpinan Situasi Dalam Kalangan Guru Besar Daaerah Johor. Journal of Educational Management, 121-144.

Lokman Mohd Tahir, Rohaya Talib, Hamimah Mohd Naim, Mohamad Berhanddin Musah. (2017). Penilaian Psikometrik Instrumen Kesediaan Guru sebagai Pemimpin Guru. UTM Skudai.

Mastura Bt. Idris. (2013). Amalan Rangka Kepimpinan Pengetua Serta Hubung Kaitnya dengan Komitmen Guru di Dua Buah Sekolah Menengah Kluster Kecemerlangan di Daerah Muar. Universiti Teknologi Malaysia. (Tesis Tidak Diterbitkan) (Tesis Ijazah Sarjana Pendidikan (Pengurusan dan Pentadbiran).

Mohana Muniandy dan Faridah Mydin Kutty. (2019). Impak Beban Tugas Terhadap Prestasi Kerja Guru Di Maktab Rendah Sains MARA. Jurnal Dunia Pendidikan, 1(1), 9-17, 2019.

Mohd Khairy Bazli dan Bity Salwana Alias. (2000). Hubungan antara Kepimpinan Multidimensi Guru Besar dan Kepuasan Kerja Guru. Jurnal Pendidikan Malaysia, Universiti Kebangsaan Malaysia.

Neuman, W. L. (2006). Social Research Methods: Qualitative and Quantitative Approaches (5th ed.). Boston: Pearson Education, Inc.

Nomura, K. 1999. Learning to Lead. Thrust for Educational Leadership, (2), 18-20.

Noraziyanah Md Jais dan Aida Hanim Hamid. (2019). The Relationship Between Headteacher Multidimensional Leadership Practices with Teacher Commitment Under School Transformation Program 2025. International Journal of Mdern Education, 1(2):13-26.

Perlman, D.J. (2013). Effective Teaching and Motivation: Application Of Self-Determination Theory. Journal of Research, Policy \& Practice of Teachers \& Teacher Education, 3(2): 31-37.

Philip, W.E. (1993). The Effectiveness of Cognitive Behavioral Stress Reduction Program In Outplacement Counseling. Dissertation abstract International Section. A Humanities \& Social Science.

Purkey, S.C. and Smith, M.S. (1982). Too Soon to Cheer? Synthesis Of Research on Effective Schools. Educational Leadership, 40(12): 64-69.

Rhodes, V., Steven, D. and Hemming, H. (2011). Creating positive culture in a New Urban High School. The High school Journal-Spring 2011.

Saphier, J., \& King, N. (1985). Good Seeds Grow in Strong Cultures. Educational Leadership, 42(6), 67-74.

Schein, E.H. (1992). Organizational Culture and Leadership: A Dynamic View. San Francisco: Jossey-Bass.

Shamsudeen Abdul Aziz. (2005). Amalan Pengurusan Berasaskan Sekolah Di Sekolah Swasta Di Malaysia: Satu Tinjauan. Universiti KebangsaanMalaysia.(Tesis Tidak Diterbitkan) (Tesis Doktor Falsafah). 